\title{
A biblioterapia como campo de atuação para o bibliotecário ${ }^{1}$
}

\author{
Bibliotherapy as a field of activity for the librarian
}

Virginia BENTES PINTO²

R E S U M O

A B S T R A C T

Reflexão sobre o campo de atuação do bibliotecário, que recorre ao conceito proposto pelo sociólogo francês Pierre Bourdieu, considerando que o campo de atuação, tanto para este profissional como para qualquer outro, implica, antes de tudo, perceber que cada profissão está vinculada ao saber, ao saberfazer e também a um fazer-saber. Em seguida, apresenta algumas reflexões sobre a história da Biblioteconomia e a biblioterapia como campo de trabalho para o bibliotecário. Entende-se a biblioterapia como uma prática leitora que utiliza textos verbais e não verbais como coadjuvantes no tratamento de pessoas acometidas por doenças físicas ou mentais ou, ainda, que enfrentam crise ou dificuldades em momentos tais como os de exclusão, ou integração social, de afastamento do convívio familiar, e de comunicação, entre outros.

Palavras-chave: bibliotecário, campo de atuação, biblioterapia, biblioteconomia-história.

This is a reflection about the librarian's field of activity, which, based on the concept proposed by the French sociologist Pierre Bourdieu, considers that the field of activity for that professional, as well as for any other, presupposes, first of all, the perception that each profession is related to a knowledge, to a "know how to do", and also, to a "make someone know". We further present some reflections about the history of Library Science and bibliotherapy as work fields for the

\footnotetext{
1 Baseado na Palestra proferida durante a III Semana de Biblioteconomia, realizada na Universidade Federal do Ceará no periodo de 1 a 2 de abril de 2004

2 Docente, Departamento de Ciências da Informação, Universidade Federal do Ceará. Av. da Universidade, 2762, Benfica, 60020-080,Fortaleza,CE, Brasil.E-mail:<vbentes@ufc.br>.

Recebido em 5/11/2004 e aceito para publicação em 18/2/2005.
} 
librarian. Bibliotherapy is understood as a reading practice that uses verbal and non-verbal texts to help in the treatment of people going through physical or mental diseases, or/and also, facing crisis or difficulties, in times of exclusion, social integration, distance from family members, communication, among others.

Key words: librarian, field of activity, bibliotherapy, library science-history.

\section{N T R O D U Ç Ã O}

Abordar o tema campo de atuação, tanto para o profissional bibliotecário, como para qualquer outro, não é simplesmente apresentar um elenco de tarefas concernentes ao domínio; muito pelo contrário, implica, antes de tudo, perceber que cada profissão está vinculada ao saber, ao saber-fazer e também a um fazer-saber. Charaudeau (1997, p.43) mostra que o saber é estruturado segundo a perspectiva do olhar do homem sobre o mundo. "Voltado para o mundo, o olhar tende a descrever este mundo em categorias de conhecimentos; voltado a si mesmo, o olhar tende a construir categorias de crenças. Simultaneamente, o saber se estrutura segundo a escolha da atividade discursiva com a qual o homem percebe o mundo", descrevendoo, reencontrando-o ou explicando-o. Com relação ao saber-fazer, Farah (1992, p.32) assinala que ele se constitui de um conjunto de habilidades empregadas "no exercício das atividades e sua interferência decisiva na definição de como executar as tarefas". Sendo assim, o saber-fazer está associado à representação procedimental ou declarativa do conhecimento pelo sujeito, e envolve tanto as suas habilidades no exercício das atividades, como a sua interferência decisiva na definição de como efetuar tarefas concernentes ao domínio especifico de saberes em questão. O fazer-saber é percebido por vários autores como sendo inato. Entendo que, em qualquer campo, está associado não apenas à compreensão, mas também ao processo de construção e comunicação do conhecimento. É bom lembrar, entretanto, que o saber, o saber-fazer e o fazer-saber, como dizem respeito aos humanos, são, por conseguinte, dinâmicos, e recebem influências de todas as mudanças de paradigmas que afetam, tanto a sociedade como um todo, como, em particular, cada área de conhecimento.

O campo da Biblioteconomia, mais do que qualquer outro, é atingido pelas mudanças que afetam a sociedade contemporânea. Estas mudanças estão relacionadas, principalmente, às grandes transformações que interferem significativamente na vida da sociedade atual, quais sejam: 0 acelerado desenvolvimento cientifico e tecnológico, a globalização e as chamadas Novas Tecnologias da Informação e da Comunicação (NTIC). Tais fenômenos alteram a ordem cartesiana das coisas no mundo e desembocam na Certeza da Incerteza, de Pedro Demo, na crise dos paradigmas, de Thomas Kuhn, com a "Estrutura das Revoluções Científicas", na A "Lógica da Pesquisa Científica", de Karl Popper, e no "Fim das Certezas", de llya Prigogine. Essas mudanças também contribuíram para o aparecimento ou reaparecimento de conceitos ressignificados: os conceitos de hibridismo, bricolagem, mixordismos, redes, ciber's (espaços, culturas, cafés), práticas, relativismos, desterritorialização, conexões parciais, humanos e não humanos, biblioteca virtual, eletrônica ou sem parede, fluidez, desordens, já fazem parte do cotidiano.

$\mathrm{Na}$ visão de Lahary (1994), as rupturas de paradigmas afetam a todos e, certamente, ao bibliotecário. A economia é cada vez mais uma economia da informação; as indústrias cultural e de lazer mostram-se cada vez mais como indústrias da informação. Os profissionais da informação, sejam bibliotecários ou não, estão no centro destas mudanças econômicas e sociais. "O mundo é, economicamente, politicamente e biblioteconomicamente imprevisível" (LAHARY, 1994, p.2). A solidez do real gaseificou-se e, agora, vive-se o fluido e o "desfronteirado" 
e, ideologicamente, tem-se acesso a tudo. Plagiando o cantor e compositor Belchior, aliás, eu queria dizer que tudo é permitido, não somente "(...) beijar a menina, no escuro do cinema...", porém, namorar, comprar, fazer transações comerciais e bancárias, fazer palestras, ministrar aulas, fazer cirurgias... em outros mundos - fora de nosso espaço geográfico e temporal, nos ciber's. Como argumentam Bentes Pinto e Silva Neto (2003), as discussões em torno de fronteiras instransponíveis e culturas isoladas, como ainda defendem alguns analistas renitentes, tornam-se cada vez mais obsoletas. Isto, porque os meios de informação e de comunicação, em virtude do extraordinário e bemsucedido casamento que fizeram com a informática, possibilitaram a conexão entre todos os povos e nações, instituindo o território do

[...] ciberespaço e da cibercultura onde antigas, novas diferenças e múltiplas produções simbólicas circulam numa busca compulsiva de sentido. [...] [Por isto], as mudanças aqui referidas também reivindicam dos estudiosos, outras posturas interpretativas, pois a complexidade dos fenômenos contemporâneos não cabe mais na linearidade e nos reducionismos dos modelos analíticos de inspiração cartesiana. (BENTES PINTO; SILVA NETO, 2003, p.260).

Frente a este cenário de mudanças, considero que não apenas a Biblioteconomia - como subárea das ditas ciências humanas ou sociais aplicadas o Conselho Nacional de Desenvolvimento Científico e Tecnológico (CNPq) e a Coordenação de Aperfeiçoamento de Pessoal de Nível Superior (CAPES), a profissão e campo de atuação do bibliotecário - mas também outros campos do conhecimento, encontram-se diante de uma crise. Vive-se um momento crítico e complexo que traz conflitos e incertezas aos bibliotecários em relação à identidade da área e, conseqüentemente, sua inter-relação com outros. Ou seja, o ambiente exige mudanças inevitáveis tanto de natureza do campo de atuação, como de formação do pessoal, assim como dos suportes de informação: entre outras mudanças, contam-se as de estruturas arquitetônicas de bibliotecas que passaram de ambientes estáticos para dinâmicos; de suporte, indo do papel para o eletrônico; das buscas em catálogos os quais, de estáticos passaram a ser dinâmicos e fluidos. O campo da Biblioteconomia foi pego de "calças curtas", como se diz na linguagem popular, diante destas mudanças, exigindo investimento maciço no ensino e na pesquisa, a fim de que os futuros profissionais saiam capacitados para atuar em um mercado cada vez mais competitivo, especializado, globalizado e desterritorializado.

Partindo destas colocações, o foco principal desta conversa está em refletir sobre o campo de atuação da Biblioteconomia, no contexto da sociedade contemporânea, para, em seguida, pensar sobre a Biblioterapia, como mais uma possibilidade de atuação para o bibliotecário.

\section{Biblioteconomia como campo de atuação}

\section{Campo de atuação}

Embora o conceito de campo já tenha sido discutido por vários teóricos, é inegável a contribuição do sociólogo francês Pierre Bourdieu para o seu aprofundamento e operacionalização. O campo pode ser entendido como "um espaço de posições e relações minimamente institucionalizadas ou então em processo de institucionalização", no qual a autonomia se define em relação à autonomia de outros campos pertinentes, em um modelo co-determinado de acordo com as hierarquias complexas, variáveis e cruzadas, existentes entre os campos. Além desta institucionalização e deste modelo de codeterminação, Bourdieu (1994, p.6) reflete sobre o campo como um espaço social, onde estão em jogo relações de conflito entre as forças de 
natureza, tanto econômica, como simbólica. $\mathrm{Na}$ compreensão de Rodrigues (1990, p.142-144), o campo social constitui um sujeito de enunciação, com a "capacidade de impor com legitimidade indiscutível algo ao conjunto do tecido social". O autor continua sua reflexão, afirmando ser necessário atingir um nível de especialização do saber instrumental a fim de obter autoridade, publicamente reconhecida, para ditar as regras das conformidades expressiva e pragmática (RODRIGUES, 1990, p.175).

Partindo destas reflexões, entendo que a Biblioteconomia é um campo com certa especificidade e relativa autonomia, uma vez que possui regras e normas específicas para legitimar seus discursos e suas ações. Além do mais, para que os bibliotecários possam efetivar seu exercício profissional com legitimidade, são exigidas habilidades e competências próprias deste campo; em outras palavras, o indivíduo precisa dominar o saber, o saber-fazer e o fazer-saber da profissão. Ou seja, "é pelo saber instrumental que se instaura o processo de autonomização dos indivíduos em relação às instâncias tradicionais de legitimação do discurso e da ação" (RODRIGUES, 1994, p.175). Por exemplo, além de professor, pesquisador, gestor de unidades de informação, ou responsável pelo planejamento de desenvolvimento de acervos, o bibliotecário também ocupa o papel de mediador entre a comunidade de usuários e o espaço documentário ou de informação. Penso assim porque, além de sua natureza de campo no espaço social, o específico do fazer bibliotecário também produz, representa, enuncia e interpreta aspectos tratados em documentos de todos os outros campos, visando contribuir para o acesso ao conhecimento registrado em suporte material, seja papel ou eletrônico. Isto vem ao encontro do habitus de Bourdieu (1983). O habitus é um "sistema de disposições adquiridas pela aprendizagem implícita ou explícita que funciona como um sistema de esquemas geradores [...] de estratégias que podem ser objetivamente afins aos interesses objetivos de seus autores sem terem sido expressamente concebidas para este fim." (BOURDIEU, 1983, p.94).

Mesmo cumprindo todos os requisitos institucionalizados pelo desenho curricular dos cursos de Biblioteconomia, este campo também enfrenta constantes incompreensões, acerca da sua legitimidade social e simbólica no que diz respeito ao entendimento do seu saber, do seu saber-fazer e do seu fazer-saber. Ainda com arrimo em Bourdieu (1983, p.83), no meu entendimento, a Biblioteconomia é o "lugar de uma oposição entre duas lógicas e dois princípios de legitimação", sendo uma baseada em critérios internos, e outra, em critérios externos. A primeira diz respeito ao reconhecimento de seus pares, pois, além do grau de consonância instituído por um conjunto de valores e de princípios socialmente construídos a partir da profissão, também se confronta com a adesão ou ruptura em face deles. A segunda diz respeito ao não-reconhecimento da sociedade (usuários e não-usuários), que são incapazes de sustentar e reconhecer o prestígio dos profissionais deste campo, o qual seria legitimado pela sociedade e, reconhecidamente, pelo mercado de trabalho.

Bourdieu (1994) mostra, ainda, que a importância de um campo social advém do "monopólio" do seu fazer e do seu saber-fazer e eu acrescento, do seu fazer-saber. No caso da Biblioteconomia, este monopólio parece recair somente sobre o domínio das técnicas de produção, organização, disseminação e recuperação de documentos. Os próprios bibliotecários e a sociedade parecem não reconhecer outros saberes do campo, fazendo com que a sua notoriedade perante o conjunto da sociedade seja ratificada quase sempre em relação aos seus aspectos pragmáticos e cartesianos, em uma percepção míope do que seja este campo de atuação. O campo da biblioteconomia não é percebido pela sociedade como sendo capaz de 
resolver uma anomalia de conhecimento ${ }^{3}$, muito menos como capaz de discutir os aspectos concernentes à informação e ao seu papel no desenvolvimento social. É preciso entender que a biblioteconomia, entre outras funções, "tem uma função coletiva em um quadro particular de indivíduos" (CALENGE, 1998, p.4).

\section{Biblioteconomia: um pouco da história}

De um ponto de vista histórico, o trabalho do bibliotecário nasceu paralelamente à criação das primeiras bibliotecas do mundo pela nobreza e pelo clero. Normalmente, exerciam as funções biblioteconômicas, os eruditos, homens (não mulheres) das letras ou eclesiásticos, sem qualquer formação bibliotecária estruturada. Esses bibliotecários atuavam como conselheiros e também auxiliavam seus usuários na recuperação da informação.

O ano de 1751 marca o aparecimento do termo bibliotecário, proposto por Diderot e D'Alembert, e divulgado em um artigo da conhecida Enciclopédia. Nesta obra o bibliotecário é definido como "Aquele que é responsável pela guarda, preservação, organização e pelo crescimento dos livros de uma biblioteca. Ele pode ter também funções literárias que demandam talento." (DIDEROT; D’ALEMBERT, 1993, p.212). Neste conceito, percebe-se tanto a aproximação da imagem do bibliotecário à do erudito, como também ao papel de conservador dos acervos antigos, e não como gestor de grandes coleções que pudessem atender a um grande número de usuários. Este "enclausuramento" mostra o distanciamento entre ele e aqueles que vinham às bibliotecas em busca de informações, fato que certamente contribuiu para se criar uma visão estereotipada e tatuada no imaginário coletivo ou quem sabe real de que o bibliotecário se preocupa com a guarda e ordem de documentos e não atua como o mediador de seu acesso, muito menos como educador.

Esta imagem do bibliotecário erudito permaneceu até o final do século XIX, quando da institucionalização da formação escolar desse profissional, com a criação, em 1873, do primeiro curso de Biblioteconomia, na Escola de Chartes - França, cujo enfoque pautado no currículo era humanístico. Este curso visava formar o profissional para responder às demandas das próprias instituições, que viam seu acervo informacional crescer sem possibilidade de que os documentos pudessem ser acessados com eficácia, assim como às do público, que já não era tão passivo, pois havia herdado a arte das reivindicaçõesdo Renascimento. Com a criação desse curso, foi expedido o primeiro diploma profissional, denominado Certificado de Aptidão às Funções de Bibliotecário (CAFB). Passados 14 anos, ou seja, em 1887, Melvil Dewey funda e implanta o segundo curso, denominado School of Library Economy, na Universidade de Colúmbia nos Estados Unidos, sendo contempladas pelo currículo matérias de cunho técnico.

O pioneirismo da França e dos Estados Unidos chegou à América Latina. Em 1911, o então diretor da Biblioteca Nacional, Manuel Cícero Peregrino da Silva, instalou no Brasil o primeiro curso de Biblioteconomia, nas dependências daquela Biblioteca, sendo considerado o Terceiro no mundo. A criação deste curso foi arrimada nos artigos 34 a 41 do Decreto $n=8.835$, de 11.07.1911, que aprovou o regulamento da Biblioteca Nacional; entretanto, o início de seu

\footnotetext{
${ }^{3}$ A anomalia do conhecimento foi defendida por Belkin (1978 apud BENTES PINTO, 1999, p.33), como um modelo de representação, no qual "the recipient instigates the communication system by recognizing an anomaly in her/his state of knowledge, this recognition being akin to the partition of generator'state of knowledge which identifies the conceptual structure to be communicated. The recipient then converts this anomalous state of knowledge (ASK) into some communicable structure (e.g. a request), which is used to retrieve from the corpus of texts some text or texts which might be appropriate for resolving the anomaly. The recipient interprets the text to discover the conceptual structure underlying it, this structure interacts with the recipients's ASK, and the recipient then makes a decision as to whether the anomaly has been sufficently resolved. If yes, the system is closed, if not the system is reinstingated with the new ASK as its basis".
} 
funcionamento deu-se somente no ano de 1915. Seu objetivo fundamental era formar bibliotecários para atuar na própria Biblioteca Nacional, a fim de situá-la em condições compatíveis com as européias (MUELLER, 1985). Ou seja, este curso não diferia dos demais, criados até então; pautava-se no modelo da Escola de Chartes, em França, contemplando em seu currículo uma formação humanística. Em 1929, o MacKenzie College criou seu Curso de Biblioteconomia, coordenado pela bibliotecária americana Dorothy Muriel Gedds, naturalmente seguindo o modelo americano, que privilegiava uma formação mais voltada para as técnicas. Em 1936, o Departamento Cultural da Prefeitura de São Paulo instituiu mais um curso de Biblioteconomia, para atender as suas necessidades.

No Ceará, a criação do curso de Biblioteconomia deu-se em 17 de fevereiro de 1964, na Universidade Federal do Ceará (UFC), tendo seu funcionamento autorizado pela Resolução de $\mathrm{n}^{\circ} 174$, de 22 de janeiro de 1965, para o primeiro semestre daquele ano. Iniciou-se com 20 alunos e a sua estrutura curricular era de 24 disciplinas, com a duração de três anos. Neste ano de 2004, - Curso de Graduação Biblioteconomia comemora 40 anos qualificando pessoas ao exercício da profissão de bibliotecários, enquanto a Universidade Federal do Ceará comemora seus 50 anos. A aprovação do curso foi lançada por ocasião do $3^{\circ}$ Congresso Brasileiro de Biblioteconomia e Documentação, realizado em Fortaleza. A criação e funcionamento deste curso deve-se ao empenho da bibliotecária Lydia de Queiroz Sambaquy que vinha insistindo com o Prof. Antonio Martins Filho, para a implantação do curso no Ceará. Como se pode observar, a implantação do curso ocorreu aproximadamente a 45 dias da efervescência do golpe militar, quando então estava em plena ascensão nacional o Estado do Ceará, em virtude da posição ocupada pelo então Marechal Humberto de Alencar Castello Branco. Como o curso de França e outros cursos, o curso da UFC, também deve sua implantação à finalidade especifica de suprir a demanda da própria Universidade, que precisava criar suas bibliotecas para atender os cursos que já tinham sido instituídos e os que estavam por vir. Segundo a professora Costa (1991, p.9), "o magistério parece não ter sido opção natural dos professores o que não impediu o esforço e o interesse em defesa do espaço que a Biblioteconomia iria ocupar no desenvolvimento profissional. Embora a ênfase do Curso tenha se voltado para a técnica e não para aspectos humanistas". Conforme salienta Cysne (1993, p.6), esta "iniciativa trouxe benefícios para o Estado e desenvolvimento para a área no Ceará". Conquanto se tenha consciência de que o curso já atingiu a sua maioridade, percebe-se que muito ainda precisa ser feito a fim de que sejam colocados no mercado profissionais adequadamente qualificados para o exercício da profissão, incluindo-se as competências e as habilidades para lidar com as ferramentas tecnológicas cada vez mais sofisticadas, bem como para analisar e propor soluções aos problemas e anomalias informacionais advindos do excesso de informação e da necessidade de acessá-la.

Uma vez institucionalizado o ensino de Biblioteconomia e, conseqüentemente, a profissão de bibliotecário, o passo seguinte seria fortalecê-la, com o campo acadêmico,

[...] reforçando-a com meios para fazer valer sua presença no mundo da Academia, como legítima arena da formulação e transmissão do conhecimento científico na área e como liderança na concepção de novas idéias e soluções sistematizadas a partir da investigação do mundo da prática, isto é, da empiria bibliotecária. (SOUZA, 2003, p.1).

No início do século $X X$, os programas de pós-graduação foram criados, destacando-se os cursos de doutoramentos em Biblioteconomia, não apenas "como operação acadêmica, mas também política de afirmação da cientificidade 
da atuação bibliotecária nos Estados Unidos e, no mundo" (SOUZA, 2003, p.1).

Ainda como forma de respaldar a profissão, surgiram as primeiras associações, conselhos e outros organismos de classe: em 1906, a Associação de Bibliotecários Franceses (ABF); entre as décadas de 1920 e 1930, sob a liderança de Rubens Borba de Moraes, a Associação Paulista de Bibliotecários (APB), responsável pela criação da Federação Brasileira de Associações de Bibliotecários (FEBAB). Outro acontecimento marcante para o campo da Biblioteconomia no Brasil foi a regulamentação da profissão em 1958, com a Portaria no 162, do Ministério do Trabalho e Previdência Social (MTPS), no Serviço Público Federal, sendo incluída no $19^{\circ}$ grupo das profissões liberais. Em 1962, veio a coroação de todos esses esforços, com a aprovação da Lei no 4084 , que regula, até hoje, o exercício profissional do bibliotecário no Brasil e estabelece as prerrogativas dos portadores de diploma em Biblioteconomia no País. Também no ano de 1962, o Conselho Federal de Educação, por meio da Resolução no 3261, estabeleceu o currículo mínimo para o ensino de Biblioteconomia no país, fixando a duração do curso em 3 anos e, em 12, o número das disciplinas obrigatórias. Ainda em 1962, aconteceu outro fato marcante para a Biblioteconomia; a regulamentação da Lei $n-4084$, veio com o Decreto no 56725/1962 que, entre outras coisas, possibilitou a instalação do conselho federal e dos conselhos regionais de Biblioteconomia. Já em 22 de outubro de 1965, pela Portaria no 585 do Ministério do Trabalho e Previdência Social (MTPS), foi instituído o Grupo de Trabalho para coordenar a realização da eleição da primeira diretoria do Conselho Federal de Biblioteconomia (CFB). Após ser institucionalizada a profissão, dado o desenvolvimento da sociedade contemporânea, as instituições de ensino superior buscam traçar o novo perfil de conhecimentos e habilidades necessários ao bibliotecário atual, de forma a atender às crescentes exigências do mercado da informa- ção. Assim, a Special Librarian Association (SLA) (GOMMEZ-FERNANDEZ, 1999) assevera que, para atuar no campo profissional, o bibliotecário precisa adquirir e dominar novos conhecimentos, habilidades profissionais e qualidades pessoais. Em relação aos novos conhecimentos e habilidades, a SLA sugere que os bibliotecários devem:

a) possuir conhecimentos suficientes dos recursos informacionais, incluindo a habilidade de avaliá-los e filtrá-los criticamente; b) conhecer os temas de suas organizações e também os seus clientes; c) desenvolver a gestão de serviços; d) promover a capacitação e fornecer os suportes para os usuários dos serviços de informação; e) avaliar as necessidades e planejar modelos de serviços e produtos informacionais; f) desenvolver produtos de informação especializados para o monitoramento informacional interno e externo da organização ou para seus usuários individuais; e g) avaliar os resultados do uso efetivo da informação.

No que concerne às qualidades pessoais, destacam-se: a) o compromisso com a qualidade de seus serviços; b) a motivação para buscar novas oportunidades, tanto em bibliotecas, como noutras unidades de documentação; c) a associação e as alianças com outros profissionais e instituições, demonstrando sua capacidade de trabalhar em equipe; $d$ ) a habilidade de comunicação, de modo a saber negociar e captar novas oportunidades e despertar confiança e respeito; e) o compromisso com a educação continuada e o desenvolvimento da profissão; f) a flexibilidade e as atitudes positivas diante das mudanças.

Visando a acompanhar as quebras de paradigmas que a sociedade contemporânea enfrenta, e que afetam todas as profissões, a Diretion de l'Information Scientifique et Technique des Bibliotheques (DISTB) organismo francês, fez uma pesquisa entre os anos de 1994 e 1995, a fim de identificar o rol de ofícios do campo da 
Biblioteconomia agrupando-os em quatro grandes categorias: atividades relacionadas com as coleções; ligadas ao público; relacionadas à formação, educação e pesquisa; e atividades relacionadas à conduta de projetos e de serviços. Eis alguns desses ofícios, nestas categorias:

a) Atividades relacionadas com as coleções: gerente do ciclo documentário, gerente de sistemas de informática documentária, gerente de coleções, gerente de planejamento e conservação de coleções, gerente da área de processamento técnico de documentos.

b) Atividades ligadas ao público: gerente de pessoal, gerente de serviços ao público, gerente de fluxos de informação e comunicação, criador e gerente de política de atendimento ao público, produtor de bibliografias, gestor do empréstimo entre bibliotecas e outras unidades de documentação, responsável por projetos de atividades de valorização profissional; biblioorientador.

c) Atividades relacionadas à formação, educação e pesquisa: educador, pesquisador, especialista, orientador de estudos e pesquisas relacionadas ao contexto da documentação, bibliotecas, usuários etc.

d) Atividades relacionadas à conduta de projetos e de serviços: responsável por projetos de engenharia documentária e biblioteconômica, diretor de unidades de documentação ou de serviços bibliotecários, culturais e documentaristas.

Mesmo com todas estas proposições, vale ressaltar que o campo de atuação do bibliotecário não se constrói sem que outras questões venham a lume. Neste sentido, Bertrand Callenge (1998, p.7) mostra que para a Biblioteconomia ser entendida e identificada como um campo autônomo, além dos aspectos técnicos, precisa resolver três questões:

1) A falta de literatura que possa ser utilizada pelos bibliotecários em suas problemáticas "sociocognitivas", ou seja, que os auxilie a chegar ao nível de capacidade necessária para traduzir as "questões dos usuários". É preciso desenvolver uma cultura científica, de tal modo que sejam utilizáveis em termos de aprendizagem do saber pelos sujeitos no contexto da coletividade, visando não apenas a interpretação-reconstrução, mas também a análise da realidade social, as escolhas políticas, as políticas públicas de leitura.

2) As dificuldades em hierarquizar as múltiplas informações recolhidas para auxiliar nas tomadas de decisão. Uma vez que a realidade sociocultural, inclusive da biblioteca, é extremamente complexa, os bibliotecários são submersos por informações diversas. Portanto, o bibliotecário não pode se contentar apenas em conhecer os usuários ou o conteúdo do saber, e sim agir de tal forma a permitir que seus usuários possam se apropriar do saber, a fim de que possa justificar a existência da coleção e dos serviços prestados;

3) Como pode esse profissional articular as diferentes técnicas relacionadas ao acervo, aos serviços, à gestão de bibliotecas, de modo que sejam perceptíveis em suas interações e na sua eficácia de atendimento ao público? Novos serviços, novas aquisições, novas tecnologias, nem sempre estão sendo postas racionalmente em relação às necessidades do saber coletivo e, é aí que residem mais precisamente o objeto concreto e a legitimidade social da Biblioteconomia.

Todas estas questões precisam ser urgentemente tratadas nos currículos dos cursos de Biblioteconomia, a fim de que este campo não seja percebido pela sociedade apenas em relação aos aspectos práticos tratados pela área. Analisando os currículos existentes e os que estão sendo implantados, em todos os cursos 
de Biblioteconomia do Brasil, (cumprindo a exigência da nova Lei de Diretrizes e Bases (LDB) ou Lei Darcy Ribeiro, sancionada em dezembro de 1996), constatei que já existem muitas disciplinas transversais que certamente poderão contribuir para reverter o imaginário social do campo da Biblioteconomia e, por extensão, do bibliotecário. Faz-se necessário, porém, que esta realidade seja divulgada junto à sociedade a fim sensibilizá-la, mostrando que o bibliotecário possui respaldo teórico e técnico para o trabalho com a informação e com o documento, independentemente do suporte e da forma como se apresente, pois, como afirma Calenge (1998, p.11), "a biblioteconomia se constrói sobre modelos que exigem processos de ação", ou seja, não se pode pensar a Biblioteconomia como uma disciplina estática, mas sim como um campo dinâmico da sociedade.

\section{Biblioterapia como campo de atuação do bibliotecário}

As concepções modernas acerca da leitura, enfatizam que essa prática não pode ser entendida apenas como a decodificação de signos lingüísticos, mas também como uma prática social que contemple a produção de sentidos. Nessas concepções, as práticas leitoras se constroem multidisciplinarmente, e, neste contexto, destaca-se a biblioterapia. Bentes Pinto et al. (1995), entendem a biblioterapia como

[...] práticas leitoras que utilizam textosverbais e não-verbais, como coadjuvantes no tratamento de pessoas acometidas por doenças físicas ou mentais ou ainda que enfrentam momentos de crise ou de dificuldades - exclusão, integração social, afastamento do convívio familiar, de comunicação etc. a fim de que os sujeitos, por aproximação ou projeção, possam sentir prazer com o texto e assim encontrem respostas para a catarse de seus conflitos, sejam eles físicos, mentais, psicossociais etc.

A biblioterapia que defendo vem ao encontro das reflexões de Pintos (1999, p.1996), ao afirmar que a dor, a pena e o sofrimento "constituem pressupostos básicos da existência do homem, de tal modo que negá-los ou crer que podem ser erradicados é, em última análise, uma utopia que, caso se concretizasse, deixaria a existência humana sem sustento", portanto, se faz necessária essa compreensão, a fim de que seja possível encontrar um sentido para a vida.

A leitura, como coadjuvante no tratamento de doenças físicas ou mentais, remonta à Antiguidade, como bem aponta Götze (2004), falando de uma biblioteca para um doente que tirava proveito terapêutico da leitura, como de um medicamento. Na Idade Média, os textos sagrados eram recitados durante as cirurgias. No contexto da Psiquiatria, a leitura foi vista como tendo grande valor após 1800 , sendo bastante intensificada por médicos, nos Estados Unidos, no período de 1802 a 1853. Na Biblioteconomia, o uso da leitura como profilaxia, se deu a partir de 1906, e na psicologia, desde 1946.

Embora a prática biblioterapêutica seja adotada desde a Antiguidade, a literatura mostra que, somente por volta de 1916, o termo biblioterapia apareceu, tendo sido cunhado por Samuel McChord Crothers, em artigo publicado no Atlantic Monthy. Etimologicamente a biblioterapia tem origem no grego biblion (livro) e therapeuticaorum (tratamento). Entendida deste modo, poder-se-ia dizer que a biblioterapia seria a terapia por meio da leitura de livros, o que constituiria uma compreensão reducionista do termo. Entendo que a biblioterapia utiliza outras ferramentas, contemplando as várias formas de leitura, por exemplo, de textos não verbais (jogos, imagens, música). Portanto, trata-se de uma vivência que se apóia em vários 
domínios e, portanto, multidisciplinar. Corroborando isto, Frankl (1977, p.100), ao proferir a conferência de abertura da Feira do Livro da Áustria, fala do poder da leitura como possibilidade terapêutica, defendendo mais uma vez a biblioterapia, não restrita ao livro, porém ao poder da palavra. Assim ele se expressa:

[...] os escritores que atravessam o inferno da desesperança e que experimentam a aparente carência de sentido da vida podem oferecer o seu sofrimento, como um sacrifício, no altar do gênero humano. As suas revelações ajudarão o leitor que sofra estado idêntico a superá-lo. (FRANKL, 1984, p.100).

É importante ressaltar, no entanto, que somente a leitura, sem um acompanhamento terapêutico, não se traduz em biblioterapia, pois esta atividade é pautada no encontro entre o individuo que está enfrentando uma situação especifica, que busca encontrar o sentido para a sua vida, e aquele que possibilita alguns recursos para a concretização deste intento, ou seja, o bibliotecário com formação terapêutica, o psicólogo, o psicoterapeuta, o psiquiatra, ou ainda o bibliotecário em uma atividade conjunta com estes profissionais.

Por volta de 1904, a biblioterapia, como prática empírica, passou a constituir em disciplina do campo da Biblioteconomia, tendo sido bastante utilizada nas bibliotecas públicas e em bibliotecas de hospitais. De acordo com Pereira (1996, p.38), esta prática floresceu "durante a primeira guerra mundial, quando bibliotecários leigos, notadamente da Cruz Vermelha, ajudaram a construir rapidamente bibliotecas nos hospitais do exército". A pesquisa comprovando a leitura como recurso terapêutico, entretanto, só foi discutida cientificamente em 1949 por Caroline Shrodes, em sua tese de doutorado intitulada "Bibliotherapy: a theoretical and clinicalexperimental study", defendida na Universidade de Berkeley, Califórnia, nos Estados Unidos. Por volta dos anos 1950, esta comprovação estava ratificada em cerca de 401 artigos publicados em periódicos considerados científicos, percebendo-se aí a consolidação da biblioterapia. As discussões em torno da biblioterapia continuavam em pauta e a American Library Association (1957) criou um comitê destinado a cuidar destas questões - American Library Association Biblioterapy Committee. Segundo Pereira (1996), este comitê coordena uma pesquisa mostrando a natureza e a extensão da atividade biblioterapêutica desenvolvida no Hospital Libraries Division.

No Brasil, as experiências com a biblioterapia foram implementadas em hospitais de São Paulo, no Instituto dos Cegos em João Pessoa, Instituto dos Cegos da Paraíba "Adalgisa Cunha", em hospitais de Belém, etc. No Ceará, o Curso de Biblioteconomia da Universidade Federal do Ceará foi o pioneiro da biblioterapia, com um projeto de pesquisa ${ }^{4}$ implantado no bloco de oncologia do Hospital Infantil Albert Sabin, para crianças com câncer, tendo lá permanecido até dezembro de 2000. Em 1995, outro projeto foi posto em prática no "Lar Torres de Melo", com pessoas idosas ${ }^{5}$. Mais um projeto na mesma linha foi implantado na "Casa de Nazaré"6, em 2000. A partir de março 2001 registrou-se outra experiência com crianças, residentes na "Casa da Criança", onde aconteceu até março de 2003. Tais experiências são implementadas como projetos interdisciplinares, notadamente entre os cursos de Biblioteconomia, Letras e Psicologia, por intermédio do Núcleo Cearense de Pesquisa da Criança (NUCEPEC). Seus resultados já somam vários artigos apresentados e publicados em anais de eventos nacionais e internacionais, assim como

\footnotetext{
4 Projeto de pesquisa desenvolvido pela Profa. Virginia Bentes Pinto, como bolsista do PIBIC-CNPq no período de março de 1994 a dezembro de 1995. Quando da saída da professora para doutoramento, o projeto passou a ser de extensão.

5 Projeto desenvolvido pela Profa. Edna Gomes Pinheiro

${ }^{6}$ Projeto desenvolvido pelos Profa. Ana Maria Sá de Carvalho e Casemiro Silva Neto.
} 
uma dissertação de mestrado, defendida por Edna Gomes Pinheiro, no Curso de Mestrado em Ciência da Informação (UFPB).

Segundo Pintos (1999, p.22), a leitura terapêutica envolve aos poucos o individuo em um estado de meditação, fazendo com que

[...] certas vivências interiores e percepções vão adquirindo maior intensidade. Nestas circunstâncias os pacientes acabam compreendendo intuitivamente o conteúdo da mensagem que a narrativa encerra, [...]. Neste momento, o paciente se aproxima de si mesmo de maneira mais relaxada e efetiva.

$\mathrm{O}$ ato da leitura demanda necessariamente do leitor a construção de sentidos sobre o que está lendo, podendo este emocionar-se, tanto com a leitura de livros, como escutando uma música ou assistindo a um filme. Essas observações foram vivenciadas por nós durante a implantação e o desenvolvimento de programas de biblioterapia com crianças acometidas pelo câncer, crianças em situação de risco e pessoas idosas morando em abrigos.

Mesmo que esta atividade seja de enorme importância para as pessoas que estejam vivendo certas crises, seu emprego demanda um planejamento bem estruturado, necessitando-se fazer uma seleção das atividades, de leituras a serem adotadas, para que estas não venham a causar transtornos aos participantes. Pittakavi (1981), estudando a biblioterapia com pessoas doentes, sugere que, ao selecionar os materiais a serem utilizados, devem-se levar em conta: o interesse e o nível de conhecimento dos pacientes; o prognóstico sobre as condições de saúde dos pacientes e as condições para desenvolver a atividade. Além desses aspectos, dadas minhas experiências com esta prática, observo que um programa de biblioterapia deve considerar também o objetivo, para o qual a atividade será utilizada. Em outras palavras, as pessoas e suas necessidades são particulares, portanto, um programa de biblioterapia deve ser construído em função de seus interesses e das circunstâncias concretas que cada participante vivencia. Esclareço, porém: a concretização de um programa de biblioterapia demanda espaço apropriado, que possa contribuir para que o leitor se expresse por gestos e palavras, e onde o biblioterapeuta possa interagir com ele, encorajando-o em suas expressões a fim de que possa encontrar respostas para seus conflitos. De acordo com Pintos (1999), um programa de biblioterapia leva o participante a perceber que ele não é o primeiro a sentir o problema; solidarizar-se com o participante a fim de que ele perceba os valores envolvidos nas suas vivências; possibilita a ele encarar a realidade de seu problema, levando-o a perceber as suas possíveis soluções. Portanto, está relacionado ao ato de sarar, que é ordenado pelo individuo que está enfrentando problemas de saúde, e, como processo se produz e se concretiza de dentro para fora.

As pesquisas mostram claramente os benefícios que a biblioterapia traz aos que participam desta vivência. Pintos (1999) destaca os seguintes aspectos da atividade: não constitui risco; as leituras são aceitas pelos pacientes, uma vez que não são percebidas como intrusas; reduz o nível de resistência psicológica dos pacientes e por isto dá agilidade ao processo de trocas, à interação; oferece novos modelos de flexibilidade apontando outros esquemas de respostas em situações similares; e estimula a independência do paciente, que busca a cura por si mesmo.

\section{CONSIDERAÇÕ ES FINAIS}

Como arremate desta intervenção, saliento minha certeza de que a Biblioteconomia é um campo de atuação respaldado pela educação formal, com regras e normas especificas a legitimarem seus discursos teóricos e técnicos. Também reconheço, entretanto, o fato de que 
esta área ainda enfrenta inúmeros problemas com relação ao reconhecimento e legitimação pela sociedade e também, de certa forma, pelos seus pares. Isto exige um trabalho de propagação maciço junto à sociedade, a fim de sensibilizá-la ao respaldo teórico e técnico que os bibliotecários possuem para o exercício de seu trabalho.

Ressalvo também que a biblioterapia é uma seara de atuação para o bibliotecário, porém a sua prática necessita de conhecimentos do terreno da psicoterapia; portanto essa vivência deveria ser implementada conjuntamente com psicólogos, terapeutas e outros profissionais desse ramo. Daí por que é interessante que, nas discussões travadas no âmbito dos cursos de Biblioteconomia, em virtude da implantação dos seus projetos políticos pedagógicos, a biblioterapia como lócus de ação do profissional de informação (bibliotecário) também seja contemplada, de maneira a se oferecerem oportunidades aos que buscam conhecimentos sobre esta disciplina.

Apesar das ameaças que as mudanças de paradigmas nos acenam, é preciso procurar caminhos, porém, junto às oportunidades e benefícios, em proveito da discussão sobre esse espaço fértil, a biblioteconomia, e do seu reconhecimento pela sociedade.

\section{REFERÊ NCIAS}

BENTES PINTO, V. et al. O uso da biblioterapia como coadjuvante no tratamento de crianças portadoras de câncer do Hospital Albert Sabin. In: INFO 95, 1995. Proceedings... Havana: IDICT, 1995.

BENTES PINTO, V. La représentation des connaissances dans le contexte de la documentation technique: proposition d'un modèle d'indexation, 1999. 389f. Thèse (Doctorat en Sciences de l'information et de la communication) - Université Stendhal Grenoble 3, Grenoble, 1999.

BENTES PINTO, V.; SILVA NETO, C. Ciberespaço: leituras e memórias cearenses na oura rede. In: CARVALHO, G. (Org.). Bonito pra chover. ensaios sobre a cultura cearense. Fortaleza: Edições Demócrito Rocha, 2003. p.259-270.

BOURDIEU, P. Questões de sociologia. Rio de Janeiro: Marco Zero, 1983. p.83-94.

BOURDIEU, P. O poder simbólico. Rio de Janeiro: Bertrand Brasil, 1989. 311p.

BOURDIEU, P. Sur la television, suivi de l'emprise du journalisme. Paris: Liber, 1994. p.6.

CALENGE, B. Peut-on définir la bibliothéconomie? Bulletin des Bibliothèques de Fance, Paris, t.43, n.2, p.8-20, 1998.

CHARAUDEAU, P. La parole confisqué: un genre televisual. Paris: Dunod, 1997. p.43.

COSTA, M.F.O. Análise critica do ensino de biblioteconomia no Ceará: comentários preliminares. Fortaleza, 1991. p.9. Mimeografado.
CROTHERS, S.M. A lieratury clinic. Atlantic Monthly, v.118, p.291-301, 1916. Available from: <http:// scholar.lib.vt.edu/ejournals/ALAN/winter95/Myracle. Html\#Crothers>. Acess: 10 Feb. 2004.

CYSNE, M.R.F.P. Biblioteconomia: dimensão social e educativa. Fortaleza: UFC, 1993. p.6.

DIDEROT, D.; D'ALEMBERT, J.R. L'encyclopédie ou dictionnaire raisonné des sciences, des arts et des métiers. Paris: Flammarion, 1993, p.212.

FARAH, M.F.S. Tecnologia processo de trabalho e construção habitacional. 1992. Tese (Doutorado) - Faculdade de Filosofia, Letras e Ciências Humanas, Universidade de São Paulo, São Paulo, 1992.

FRANKL, V.E. Psicoterapia y humanismo. Buenos Aires: Fundo de Cultura, 1977. 250p.

FRANKL, V.E. Psicoterapia y humanismo. México: Fundo de Cultura Econômica, 1984. p.100.

GOMEZ-FERNANDEZ, J.C. El profesional de la documentación. In: GARCIA GUTIERREZ, A. (Ed.). Introducción a la Documentación Informativa y Periodística. Sevilla: Editorial Mad, 1999, p.155-185. Disponível em: <http://www.arrakis.es/ãmjg/ per9.htm>. Acesso em: 10 fev. 2004.

GÖTZE, G.H. Biblioteca de enfermos. Disponível em: <http://www.el-mundo.es/salud/1994/118/ 00372.html>. Acesso em: 10 fev. 2004.

LAHARY, D. Du profil de poste au métier. Bulletin d'Informations de l'ABF, n.164, p.2, 1994. Disponível 
em: <www.google.com.br/search?q=cache:HkOU xv18k_cJ:membres.lycos.fr/vacher/profess/textes/ metier3.htm>. Acesso em: 3 mar. 2004.

MUELLER, S.P.M. O ensino da biblioteconomia no Brasil. Ciência da Informação, Brasília, v.14, n.1, p.3-15, 1985.

PEREIRA, M.M.G. Biblioterapia: proposta de um programa de leitura para portadores de deficiência visual em bibliotecas públicas. João Pessoa: Editora Universitária, 1996. p.38.

PINTOS, C.G. A logoterapia em contos: o livro como recurso terapêutico. São Paulo: Paulus, 1999, p.22.

PITAKAVI, N.S.R. Bibliotherapy: library services in the treatment of the sick. Library Scientist, v.8, p.101-106, 1981.
RODRIGUES, A.D. Estratégias de comunicação. Lisboa: Editorial Presença, 1990. p.142-144; 175. RODRIGUES, A.D. Comunicação e cultura: a experiência cultural na era da informação. Lisboa: Editorial Presença, 1994. p.142-175.

SHRODES, C. Bibliotherapy: a theoretical and clinical-experimental study. 1949. 344f. Dissertation (Doctor of Philosophy in Education) - University of California, Berkeley.

SOUZA, F.C. A escola de Biblioteconomia e a ancoragem da profissão de bibliotecário. Informação \& Sociedade: estudos, p.1. 2003. Disponível em<http://www.Informacaoesociedade. ufpb./1120106.pdf>. Acesso em: 3 mar. 2004. 
